\title{
Thinner changes of the retinal nerve fiber layer in patients with mild cognitive impairment and Alzheimer's disease
}

Dachuan Liư ${ }^{1 \dagger}$, Lina Zhang ${ }^{2 \dagger}$, Zhen $\mathrm{Li}^{1}$, Xuxiang Zhang ${ }^{1}$, Yue Wu${ }^{1}$, Huiqing Yang ${ }^{3}$, Baoquan Min ${ }^{3}$, Xinqing Zhang ${ }^{1}$, Daqing $\mathrm{Ma}^{4}$ and $\mathrm{Yan} \mathrm{Lu}^{1 *}$

\begin{abstract}
Background: Alzheimer's disease (AD) is the most common form of dementia and patients often have visual disorders. Mild cognitive impairment $(\mathrm{MCl})$ is characterized by a memory deficit when compared with those of a similar age and education level which could indicate an earlier onset of AD. The aim of this study is to measure the changes of the retinal nerve fiber layer (RNFL) thickness of $A D$ and $\mathrm{MCl}$ patients in comparison with the normal age controls.

Methods: The RNFL thickness was assessed using optical coherence tomography (OCT) in patients with $\mathrm{MCl}$, AD (mild, moderate and severe) and the age matched controls.

Results: The thickness of RNFL in the superior quadrant and total mean values are gradually and significantly decreased from $\mathrm{MCl}$ to severe $\mathrm{AD}$ when compared to that in the controls. There is also a significant reduction of the retinal nerve fiber layer in the inferior quadrant in severe AD patients.

Conclusions: Our data indicate that the retinal nerve fiber layer degeneration is paralleled with dementia progression. Owing to its non-invasive and cost effective nature, monitoring RNFL thickness may have a value in assessing disease progression and the efficacy of any treatments.
\end{abstract}

Keywords: Alzheimer's disease, Mild cognitive impairment, Retinal nerve fiber layer, Optical coherence tomography

\section{Background}

Alzheimer's disease (AD) is the most common form of dementia and is characterized by cognitive deficits including progressive memory disturbances, aphasia, apraxia and agnosia. AD patients also have visual problems affecting visual acuity [1], stereopsis, colour vision, spatial contrast sensitivity and ocular motility [2]. The typical pathological changes in $\mathrm{AD}$ are senile plaques and neurofibrillary tangles in the central nervous system (CNS). Mild cognitive impairment (MCI) is defined as impairment in cognitive functions with otherwise normal performance of activities of daily life [3]. MCI is a broad term that encompasses several subtypes of cognitive dysfunction. Amnesic MCI

\footnotetext{
*Correspondence: louiselu1964@163.com

${ }^{\dagger}$ Equal contributors

'Department of Ophthalmology, Xuan Wu Hospital, Capital Medical University, Beijing 100053, China

Full list of author information is available at the end of the article
}

patients may show an early transitional stage development of $\mathrm{AD}$ and have memory impairment, but without dementia [4]. 10\%-15\% MCI suffers are most likely to progress to $\mathrm{AD}$ per year while $1 \%$ to $2 \%$ of healthy people are in a risk developing to $\mathrm{AD}[5,6]$.

Optical coherence tomography (OCT) is a well-established non-invasive examination that can assess the thickness of retinal nerve fiber layer (RNFL) and is used in various ophthalmologic diseases including glaucoma, ocular hypertension, optic neuropathy and multiple sclerosis [7]. Previous reports have demonstrated a possible degeneration of the RNFL in AD [8-15]. For example, a postmortem study by Hilton et al., found widespread axonal degeneration in the optic nerves in 8 out of 10 AD sufferers [16]. Sadun's work also suggested that the degeneration of ganglion cells were mainly observed in large M-cell axons [8]. However, other studies failed to support those findings $[17,18]$, indicating that methodological differences may be responsible for those 
different findings but this warrants further study. The aim of the present study was to determine with a sophisticated OCT method whether the thickness of the RNFL is proportionally reduced from $\mathrm{MCI}$ patients, mild $\mathrm{AD}$ to severe $\mathrm{AD}$ patients compared to that in the age-matched healthy controls.

\section{Methods}

After approval from the Ethics committee of Xuanwu Hospital, Capital Medical University, Beijing, China and written informed consent was obtained, $26 \mathrm{MCI}, 24$ mild AD patients, 24 moderate AD patients, 19 severe AD patients and 39 age-matched controls were enrolled into the study. All patients and controls were examined for visual acuity, refractive error, intraocular pressure (IOP), anterior and posterior segment biomicroscopy, dilated fundus examination.

All $\mathrm{AD}$ patients were diagnosed by the $\mathrm{AD}$ group of neurologists in the department of Neurology in Xuanwu Hospital according to the National Institute of Neurologic and Communicative Disorders and Stroke-Alzheimer's Disease and Related Disorders Association (NINCDSADRDA) [19] and the Diagnostic and Statistical Manual of Mental Disorders (DSM IV) criteria [20].

Each of the MCI patients are diagnosed by three neurologists in the department of Neurology Xuanwu hospital according to Petersen criteria [21]. The criteria for controls were: (1) no memory complaints; (2) MMSE scores above 28. Additional criteria requirements for all study subjects are: (1) Diopters: spherical $-3.00 \mathrm{DS} \sim+3.00 \mathrm{DS}$, cylinder $-3.00 \mathrm{DC} \sim+3.00 \mathrm{DC}$, anisometropia $\leq 2 \mathrm{D} ;(2)$ IOP measured three times $<21 \mathrm{mmHg}$; Exclusion criteria was: glaucoma and increased intraocular pressure, retinal detachment, retinal artery occlusion, optic neuropathy, ocular trauma or surgery, diabetes mellitus, hypertension, cerebral infarction and other diseases which may affect RNFL thickness.

OCT evaluations were done according to the standard procedures using a STRATUS OCT 3 (Carl Zeiss AG, Oberkochen, Germany). Near infrared super-luminescent diode light allows the OCT to generate two dimensional images of the retina. RNFL thickness was circularly measured around the papilla (optic disc: $3.4 \mathrm{~mm}$ ) and repeated three times per quadrant (superior, inferior, nasal and temporal) and the average of the 12 values were used for each eye as expressed in $\mu \mathrm{m}$. The threshold of scanning signal was set to be $\geq 6$.

Data are reported as mean \pm SD and statistical analysis was performed with SPSS 16.0 (SPSS Inc, Chicago, IL, USA). The differences about gender constituent ratio among controls, $\mathrm{MCI}$, mild $\mathrm{AD}$, moderate $\mathrm{AD}$ and severe $A D$ were compared with chi-square test. The differences about age, IOP, and RNFL thickness among five groups were evaluated with one-way ANOVA followed by post hoc comparison with Bonferroni correction to test the data between groups. A $p<0.05$ was considered to be of statistical significance.

\section{Results}

There was no statistically significant difference in gender, age and IOP among five groups $(P>0.05)$ (Table 1$)$.

There was a significant difference between the normal control group and $\mathrm{MCI}$ and 134 mild $\mathrm{AD}$, moderate $\mathrm{AD}$ or severe $\mathrm{AD}$ respectively in superior quadrant, inferior 135 quadrant and total mean RNFL thickness $(p<0.05)$ but no significant difference in nasal and temporal quadrant $(p>0.05)$. In the superior quadrant and total mean RNFL, compared with that in the normal control group, the RNFL thickness of the MCI, mild dementia, moderate dementia and severe dementia group were reduced 139 and there was a statistically significant difference $(p<0.05)$. Furthermore, when compared with the MCI group, the RNFL thicknesses of moderate and severe AD group were significantly decreased $(p<0.05)$. There was no significant difference in RNFL thickness among mild AD, moderate $\mathrm{AD}$ and severe $\mathrm{AD}$ groups. In the inferior quadrant, there are no significant differences $(p>0.05)$ in the MCI group, mild $\mathrm{AD}$ group and moderate $\mathrm{AD}$ group compared with the control group. In the total mean RNFL, compared with that in the normal control group, the RNFL thickness of $\mathrm{MCI}$ group, mild $\mathrm{AD}$, moderate $\mathrm{AD}$, severe $\mathrm{AD}$ were gradually reduced $(p<0.05)$ (Table 2$)$. Furthermore, when these

Table 1 The clinical data of patients with $\mathrm{MCl}$, mild, moderate, severe AD and control groups (mean \pm SD)

\begin{tabular}{|c|c|c|c|c|c|c|c|c|}
\hline & & $\begin{array}{l}\mathrm{MCl} \\
(n=26)\end{array}$ & $\begin{array}{l}\text { MI AD } \\
(n=24)\end{array}$ & $\begin{array}{l}\text { MO AD } \\
(n=24)\end{array}$ & $\begin{array}{l}\text { SE AD } \\
(n=19)\end{array}$ & $\begin{array}{l}\text { control } \\
(n=39)\end{array}$ & & $\begin{array}{l}P \\
\text { value }\end{array}$ \\
\hline \multirow[t]{2}{*}{ Sex } & M & 12 & 9 & 11 & 9 & 17 & $X^{2}=0.370$ & $>0.05$ \\
\hline & $F$ & 14 & 15 & 13 & 10 & 22 & & \\
\hline Age (y) & & $70.2 \pm 6.5$ & $71.3 \pm 4.9$ & $70.8 \pm 6.1$ & $72.1 \pm 4.6$ & $69.7 \pm 7.8$ & $F=1.341$ & $>0.05$ \\
\hline IOP (mmHg) & & $16.1 \pm 1.3$ & $15.9 \pm 2.1$ & $15.1 \pm 1.2$ & $14.4 \pm 1.2$ & $15.9 \pm 0.9$ & $F=2.260$ & $>0.05$ \\
\hline VA (logMAR) & & $0.16 \pm 0.08$ & $0.21 \pm 0.10$ & $0.33 \pm 0.01$ & $0.35 \pm 0.03$ & $0.06 \pm 0.09$ & $F=3.501$ & $<0.05$ \\
\hline
\end{tabular}

MCl: Mild cognitive impairment; AD: Alzheimer's disease; n: eyes; Ml: mild; MO: moderate.

SE: severe; M: male; F: female; IOP: intraocular pressure; VA: visual acuity. 
Table 2 RNFL thickness $(\mu \mathrm{m})$ in patients with $\mathrm{MCl}$, mild, moderate, severe AD and control subjects (mea \pm SD)

\begin{tabular}{|c|c|c|c|c|c|}
\hline & $\mathrm{MCl}$ & mild $A D$ & moderate AD & severe AD & control $F$ value \\
\hline \multirow[t]{2}{*}{$S$} & $115.14 \pm 13.51^{\mathbf{\Lambda}}$ & $111.78 \pm 11.67^{\mathbf{\Lambda}}$ & $108.89 \pm 12.42^{\boldsymbol{\Lambda}}$ & $101.56 \pm 19.32^{\boldsymbol{\Lambda}}$ & $119.10 \pm 15.34$ \\
\hline & & & & & $2.012^{*}$ \\
\hline \multirow[t]{2}{*}{ । } & $120.23 \pm 18.04$ & $115.11 \pm 10.56$ & $113.23 \pm 16.21$ & $111.41 \pm 10.64 \boldsymbol{\Lambda}$ & $125.67 \pm 11.23$ \\
\hline & & & & & $5.549^{* *}$ \\
\hline \multirow[t]{2}{*}{ N } & $74.80 \pm 12.36$ & $69.76 \pm 11.64$ & $64.41 \pm 15.87$ & $61.12 \pm 17.54$ & $79.98 \pm 12.87$ \\
\hline & & & & & 1.035 \\
\hline \multirow[t]{2}{*}{$\mathrm{T}$} & $63.78 \pm 13.16$ & $61.17 \pm 12.14$ & $60.43 \pm 11.87$ & $60.41 \pm 10.82$ & $67.34 \pm 15.27$ \\
\hline & & & & & 1.256 \\
\hline \multirow[t]{2}{*}{ M } & $95.37 \pm 17.11^{\wedge}$ & $91.61 \pm 10.10^{\Lambda}$ & $91.68 \pm 12.37^{\boldsymbol{\Delta}}$ & $87.13 \pm 17.05^{\mathbf{\Delta} \boldsymbol{~}}$ & $100.12 \pm 15.01$ \\
\hline & & & & & $7.985^{* *}$ \\
\hline
\end{tabular}

S: superior of Peripapillary RNFL thickness; I: inferior of Peripapillary RNFL thickness; N: nasal of Peripapillary RNFL thickness; T: temporal of Peripapillary RNFL thickness; M: total mean of RNFL thickness; Compared with the control group: ${ }^{\mathbf{A}} P<0.05,{ }^{\mathbf{\Delta}} P<0.01 ;$ comparison to MCl: ${ }^{*} P<0.05 \mathrm{~F}$ test: ${ }^{*} \mathrm{p}<0.05$, ${ }^{* *} \mathrm{p}<0.001$.

data were plotted together, it clearly revealed that there was a falling trend along with the disease progression (Figure 1).

\section{Discussion}

Our data indicated the thickness of RNFL in the superior quadrant and total mean RNFL was gradually decreased that with the disease progression from MCI to severe $\mathrm{AD}$. There was also a reduction of the retinal nerve fiber layer in inferior quadrant in severe $A D$ patients.

In line with our data, a previous study measuring peripapillary RNFL in AD by OCT showed that a significant thinning change of the RNFL was found in the superior

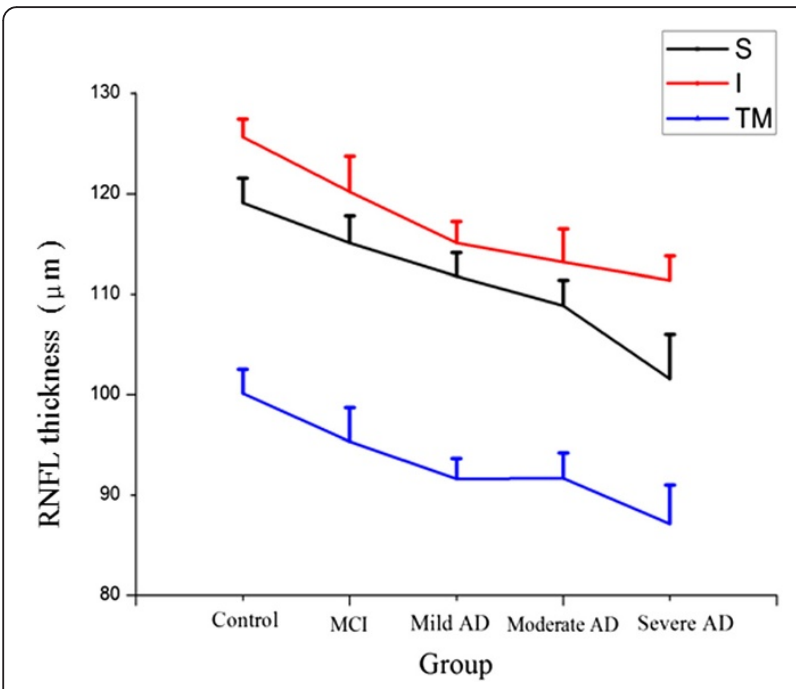

Figure 1 RNFL thickness in patients with $\mathrm{MCl}$, mild, moderate, severe $A D$ and control subjects. Line graph constructed with data from Table 2 represents the changing trend of mean RNFL thickness $(\mu \mathrm{m})$ plus variations in the superior quadrant (s), inferior quadrant (I) and total mean (TM) along with the disease progression. quadrant in patients with $\mathrm{AD}$ compared with control subjects. There were no significant differences in the inferior, temporal or nasal RNFL thicknesses between the groups [22]. Our previous study found that the superior and inferior quadrants nerve fiber layer thickness was thinning in the $\mathrm{AD}$ patients compared with the healthy controls measured by OCT [23]. Other reports [24,25] indicated that there is a clear reduction of RNFL thickness, involving all four quadrants in AD and MCI patients. Our current data suggest that there is the reduction in retinal nerve fiber layer in superior quadrant selectively in the early AD. Accompanying with the development of $\mathrm{AD}$, the degeneration of the retinal nerve fiber layer appears not only in superior quadrant, but also in inferior quadrant. The reason for such selective thinning RNFL in the superior region remains unknown. Anatomically, axons from the superior retina project via the parietal lobe portion of the optic radiation to the cuneal gyrus of the primary visual cortex, whereas axons from the inferior retina project to the lingual gyrus. In a histopathology study of cortical damage in AD, Armstrong [26] found a greater density of senile plaques and neurofibrillary tangles in the cuneal gyrus than in the lingual gyrus, and suggested that this difference may explain the predominantly superior RNFL defects in AD.

Several previous reports indicate that visual problems in AD were attributed to nerve degeneration in the primary visual cortex [27-29]. However, there have been increasing evidence that the primary visual pathways (the optic nerve and retinal degeneration) may also contribute to the visual disorders. For example, there are publications suggesting that the optic nerve and retinal degeneration existed in patients with AD $[5,7-9,16]$. That is the case in our study reported here. Accompanying the development of $\mathrm{AD}$, the degeneration of the retinal nerve fiber layer appears not only in superior quadrant, but also in inferior quadrant. However, some of the literature did not support the 
notion. For example, a previous study showed that the deficits in visual function that are known to occur in dementia of the Alzheimer's type are not related to optic nerve head structural anomalies, at least in the earlier stages of the disease [30]. Kergoat et al. analyzed fundus images, captured by scanning laser polarimetry, and they found no differences in the RNFL thickness observed between $\mathrm{AD}$ and healthy subjects [30]. Hence, this warrants further study to identify the true reason of visual disorders in $\mathrm{AD}$ and also to clarify whether visual disorders are also due to disorders of visual cortex and/or primary visual pathways.

Amyloid-beta $(A \beta)$ plaques which is also known as senile plaques have been reported in postmortem retinal tissue from patients with $\mathrm{AD}$ and the mouse model of $\mathrm{AD}$ [31-33]. We found the degree of the retinal nerve fiber layer degeneration deteriorated gradually along with $\mathrm{AD}$ development which indicates the retinal Ganglion Cell (RGC) losses may be correlated with the duration of $\mathrm{AD}$ progression [2]. Interestingly, amyloid protein has also been shown to be associated with the degeneration of RGC in a mouse model of glaucoma [34]. Therefore, amyloid accumulation in the retina of $\mathrm{AD}$ patients may result in degeneration of RGC in parallel to amyloid-related neurodegeneration in the cerebrum.

MCI constitutes a risk factor for AD. The RNFL thickness occurred in MCI patients being found in our study is striking although this warrants further study. If this is true, then it would be very valuable for patients to have general screening with OCT to further support diagnosis for a possibility to detect the earlier onset of MCI. Extensive research is being devoted to identifying individuals who are likely to develop AD from MCI [6]. Our data showing that RNFL thickness in MCI is reduced may be further evidence indicating $\mathrm{MCI}$ progression in patients while a follow-up study is needed to explore how the degree and duration of the RNFL relates to the progression from $\mathrm{MCI}$ to $\mathrm{AD}$. However, cautions must be taken due to the following reasons: 1) This is a pure observational cohort study not a trial. Large sample size is needed to further verify our current findings; 2) Petersen criteria was used to define $\mathrm{MCI}$ without further biomarkers or even evidence from PET imaging; 3) A time not spectral domain OCT was used and hence lower resolution images can be problematic for data accuracy. Nevertheless, our data reported here may guide neurologists to consider OCT to be additional tool for better diagnosis and/or treatment monitoring of dementia patients although it is very plausible to be used to clarify the severity of dementia.

\section{Conclusions}

OCT is a safe and non-invasive method which has been used to assess retinal degeneration in various ophthalmologic and neurological disorders. From our experience and the data reported here, it could be suggested that OCT can be used to improve MCI diagnosis in individuals clinically affected by subtle memory disturbances and to monitor the progression of Alzheimer's disease and evaluate effectiveness of any treatments.

\section{Abbreviations}

AD: Alzheimer's disease; MCl: Mild cognitive impairment; RNFL: Retinal nerve fiber layer thickness; OCT: Optical coherence tomography; CNS: Central nervous system.

\section{Competing interests}

The authors report no conflicts of interest. The funders had no role in the study design, data collection and analysis, decision to publish or preparation of the manuscript.

\section{Authors' contributions}

$D L, L Z$ and $Y L$ made substantial contribution to the study design, data collection, manuscript preparation and written up. ZL and YW also contributed to the data collection. HY completed with all the ophthalmic examinations while DL, XXZ (Xuxiang Zhang) and YL were involved in data analysis and interpretation of data of ophthalmic examinations. While BM and XQZ (Xinqing Zhang) were involved in analysis and interpretation of data of neurological examination and patients' diagnosis and classify. DM gave critical comments and a help for the manuscript written up. All authors read and approved the final manuscript.

\section{Acknowledgments}

The authors thank Professor Rong Wang, Center laboratory, Xuan Wu Hospital, Capital Medical University, Center of Alzheimer's Disease, Beijing Institute for Brain Disorders, Laboratory for Neurodegenerative Diseases of Ministy of Education, for help designing this study. Also thank Professor Ningli Wang, Beijing Tongren Eye Center, Beijing Tongren Hospital, Capital Medical University, for help designing and data analysis of this study. This work was supported by Beijing Municipal Science \& Technology Commission (Z141107002514116).

\section{Author details}

'Department of Ophthalmology, Xuan Wu Hospital, Capital Medical University, Beijing 100053, China. ${ }^{2}$ Department of Ophthalmology, The First Affiliated Hospital of Zhengzhou University, Zhengzhou 453003, China. ${ }^{3}$ Department of Neurology, Xuan Wu Hospital, Capital Medical University, Beijing 100053, China. ${ }^{4}$ Anaesthetics, Pain Medicine and Intensive Care, Department of Surgery and Cancer, Imperial College London, Chelsea and Westminster Hospital, London SW10 9NH, UK.

Received: 9 October 2014 Accepted: 3 February 2015

Published online: 21 February 2015

\section{References}

1. Kesler A, Vakhapova V, Korczyn AD, Naftaliev E, Neudorfer M. Retinal thickness in patients with mild cognitive impairment and Alzheimer's disease. Clin Neurol Neurosurg. 2011;113(7):523-6.

2. Risacher SL, Wudunn D, Pepin SM, MaGee TR, McDonald BC, Flashman LA, et al. Visual contrast sensitivity in Alzheimer's disease, mild cognitive impairment, and older adults with cognitive complaints. Neurobiol Aging. 2013:34(4):1133-44.

3. Werner P, Korczyn AD. Mild cognitive impairment: conceptual, assessment, ethical, and social issues. Clin Interv Aging. 2008;3(3):413-20.

4. Petersen RC, Doody R, Kurz A, Mohs RC, Morris JC, Rabins PV, et al. Current concepts in mild cognitive impairment. Arch Neurol. 2001;58(12):1985-92.

5. Petersen RC, Stevens JC, Ganguli M, Tangalos EG, Cummings JL, DeKosky ST. Practice parameter: early detection of dementia: mild cognitive impairment (an evidence-based review). Report of the quality standards subcommittee of the American Academy of Neurology. Neurology. 2001;56(9):1133-42.

6. Petersen RC. Mild cognitive impairment as a diagnostic entity. J Intern Med. 2004;256(3):183-94.

7. Jaffe GJ, Caprioli J. Optical coherence tomography to detect and manage retinal disease and glaucoma. Am J Ophthalmol. 2004;137(1):156-69. 
8. Sadun AA, Bassi CJ. Optic nerve damage in Alzheimer's disease. Ophthalmology. 1990;97(1):9-17.

9. Blanks JC, Torigoe Y, Hinton DR, Blanks RH. Retinal pathology in Alzheimer's disease I Ganglion cell loss in foveal/parafoveal retina. Neurobiol Aging. 1996;17(3):377-84.

10. Valenti DA. Alzheimer's disease: visual system review. Optometry. 2010;81 (1):12-21.

11. Larrosa JM, Garcia-Martin E, Bambo MP, Pinilla J, Polo V, Otin S, et al. Potential new diagnostic tool for Alzheimer's disease using a linear discriminant function for fourier domain optical coherence tomography. Invest Ophthalmol Vis Sci. 2014;55(5):3043-51.

12. Polo V, Garcia-Martin E, Bambo MP, Pinilla J, Larrosa JM, Satue M, et al. Reliability and validity of Cirrus and Spectralis optical coherence tomography for detecting retinal atrophy in Alzheimer's disease. Eye. 2014;28(6):680-90.

13. Kromer R, Serbecic N, Hausner L, Froelich L, Aboul-Enein F, Beutelspacher SC. Detection of retinal nerve fiber layer defects in Alzheimer's disease using SD-OCT. Front Psychiatry. 2014;5:22.

14. Shi Z, Wu Y, Wang M, Cao J, Feng W, Cheng Y, et al. Greater attenuation of retinal nerve fiber layer thickness in Alzheimer's disease patients. J Alzheimers Dis. 2014;40(2):277-83.

15. Shen $Y$, Shi Z, Jia R, Zhu Y, Cheng Y, Feng W, et al. The attenuation of retinal nerve fiber layer thickness and cognitive deterioration. Front Cell Neurosci. 2013;7:142.

16. Hinton DR, Sadun AA, Blanks JC, Miller CA. Optic-nerve degeneration in Alzheimer's disease. N Engl J Med. 1986;315(8):485-7.

17. Curcio CA, Drucker DN. Retinal ganglion cells in Alzheimer's disease and aging. Ann Neurol. 1993;33(3):248-57.

18. Davies DC, McCoubrie P, McDonald B, Jobst KA. Myelinated axon number in the optic nerve is unaffected by Alzheimer's disease. Br J Ophthalmol. 1995;79(6):596-600.

19. McKhann G, Drachman D, Folstein M, Katzman R, Price D, Stadlan EM. Clinical diagnosis of Alzheimer's disease: report of the NINCDS-ADRDA Work Group under the auspices of Department of Health and Human Services Task Force on Alzheimer's Disease. Neurology. 1984;34(7):939-44.

20. American Psychiatric Association. Diagnostic and Statistical Manual of Mental Disorders (DSM-IV). 4th ed. Washington, DC: American Psychiatric Association; 1994.

21. Petersen RC, Smith GE, Waring SC, Ivnik RJ, Tangalos EG, Kokmen E. Mild cognitive impairment: clinical characterization and outcome. Arch Neurol. 1999;56(6):760

22. Berisha F, Feke GT, Trempe CL, McMeel JW, Schepens CL. Retinal abnormalities in early Alzheimer's disease. Invest Ophthalmol Vis Sci. 2007:48(5):2285-9.

23. Lu Y, Li Z, Zhang X, Ming B, Jia J, Wang R, et al. Retinal nerve fiber layer structure abnormalities in early Alzheimer's disease: evidence in optical coherence tomography. Neurosci Lett. 2010;480(1):69-72.

24. Paquet C, Boissonnot M, Roger F, Dighiero P, Gil R, Hugon J. Abnormal retinal thickness in patients with mild cognitive impairment and Alzheimer's disease. Neurosci Lett. 2007;420(2):97-9.

25. Parisi V, Restuccia R, Fattapposta F, Mina C, Bucci MG, Pierelli F. Morphological and functional retinal impairment in Alzheimer's disease patients. Clin Neurophysiol. 2001;112(10):1860-7.

26. Armstrong RA. Visual field defects in Alzheimer's disease patients may reflect differential pathology in the primary visual cortex. Optom Vis Sci. 1996;73(11):677-82.

27. Schlotterer G, Moscovitch M, Crapper-McLachlan D. Visual processing deficits as assessed by spatial frequency contrast sensitivity and backward masking in normal ageing and Alzheimer's disease. Brain. 1984;107(Pt 1):309-25.

28. Cogan DG. Visual disturbances with focal progressive dementing disease. Am J Ophthalmol. 1985;100(1):68-72.

29. Nissen MJ, Corkin S, Buonanno FS, Growdon JH, Wray SH, Bauer J. Spatial vision in Alzheimer's disease. General findings and a case report. Arch Neurol. 1985;42(7):667-71.

30. Kergoat H, Kergoat MJ, Justino L, Chertkow H, Robillard A, Bergman H. An evaluation of the retinal nerve fiber layer thickness by scanning laser polarimetry in individuals with dementia of the Alzheimer type. Acta Ophthalmol Scand. 2001;79(2):187-91.

31. Koronyo Y, Salumbides BC, Black KL, Koronyo-Hamaoui M. Alzheimer's disease in the retina: imaging retinal abeta plaques for early diagnosis and therapy assessment. Neurodegener Dis. 2012;10(1-4):285-93.
32. Koronyo-Hamaoui M, Koronyo Y, Ljubimov AV, Miller CA, Ko MK, Black KL, et al. Identification of amyloid plaques in retinas from Alzheimer's patients and noninvasive in vivo optical imaging of retinal plaques in a mouse model. Neurolmage. 2011;54 Suppl 1:S204-17.

33. Williams PA, Thirgood RA, Oliphant H, Frizzati A, Littlewood E, Votruba M, et al. Retinal ganglion cell dendritic degeneration in a mouse model of Alzheimer's disease. Neurobiol Aging. 2013;34(7):1799-806.

34. Guo L, Duggan J, Cordeiro MF. Alzheimer's disease and retinal neurodegeneration. Curr Alzheimer Res. 2010;7(1):3-14.

\section{Submit your next manuscript to BioMed Central and take full advantage of:}

- Convenient online submission

- Thorough peer review

- No space constraints or color figure charges

- Immediate publication on acceptance

- Inclusion in PubMed, CAS, Scopus and Google Scholar

- Research which is freely available for redistribution 